\title{
Roles of African swine fever virus structural proteins in viral infection
}

\author{
Ning Jia ${ }^{1}$, Yunwen $\mathrm{Ou}^{1,2}$, Zygmunt Pejsak ${ }^{3}$, \\ Yongguang Zhang ${ }^{2}$, Jie Zhang ${ }^{2}$ \\ ${ }^{1}$ College of Veterinary Medicine, Gansu Agricultural University, Lanzhou 730070, China \\ ${ }^{2}$ State Key Laboratory of Veterinary Etiological Biology, OIE/National Foot-and-Mouth Disease Reference Laboratory, \\ Lanzhou Veterinary Research Institute, Chinese Academy of Agricultural Sciences, Lanzhou 730046, China \\ ${ }^{3}$ Department of Swine Diseases, National Veterinary Research Institute, 24-100 Pulawy, Poland \\ zhangjie03@caas.cn
}

Received: March 12, $2017 \quad$ Accepted: May 25, 2017

\begin{abstract}
African swine fever virus (ASFV) is a large, double-stranded DNA virus and the sole member of the Asfarviridae family. ASFV infects domestic pigs, wild boars, warthogs, and bush pigs, as well as soft ticks (Ornithodoros erraticus), which likely act as a vector. The major target is swine monocyte-macrophage cells. The virus can cause high fever, haemorrhagic lesions, cyanosis, anorexia, and even fatalities in domestic pigs. Currently, there is no vaccine and effective disease control strategies against its spread are culling infected pigs and maintaining high biosecurity standards. African swine fever (ASF) spread to Europe from Africa in the middle of the $20^{\text {th }}$ century, and later also to South America and the Caribbean. Since then, ASF has spread more widely and thus is still a great challenge for swine breeding. The genome of ASFV ranges in length from about 170 to $193 \mathrm{kbp}$ depending on the isolate and contains between 150 and 167 open reading frames (ORFs). The ASFV genome encodes 150 to 200 proteins, around 50 of them structural. The roles of virus structural proteins in viral infection have been described. These proteins, such as pp220, pp62, p72, p54, p30, and CD2v, serve as the major component of virus particles and have roles in attachment, entry, and replication. All studies on ASFV proteins lay a good foundation upon which to clarify the infection mechanism and develop vaccines and diagnosis methods. In this paper, the roles of ASFV structural proteins in viral infection are reviewed.
\end{abstract}

Keywords: African swine fever virus, structural proteins, viral infection, review.

\section{Introduction}

African swine fever (ASF), first identified in Kenya in 1921, had only been reported in the subSaharan region before 1957; however, the virus had spread to other regions and this led to an ASF outbreak in Lisbon, Portugal, in that year (59). Due to successful biosecurity regulations, African swine fever virus (ASFV) was then eradicated from most affected regions. However, it still remains endemic in subSaharan countries and Sardinia (18). So far, ASF has been identified in the Caucasus and Central and Eastern European regions, and in countries such as Armenia, Azerbaijan, Belarus, Ukraine, Estonia, Latvia, Lithuania, and Poland (1, 18, 56, 68). In Poland, ASFV was detected for the first time in Sokółka county in
2014. Since February 2014 and at the time of writing, 80 ASF cases in wild boars and 3 outbreaks in domestic pigs have been diagnosed in Poland $(30,36,71)$. The disease has caused heavy economic losses to the pig industry and exerted significant social influence on the world. ASF is caused by ASFV which is a linear, large, double-stranded DNA virus and the only member of the Asfarviridae family (15). Wild pigs such as warthogs and bush pigs, and soft ticks of the Ornithodoros species are the natural hosts of ASFV and they can be persistently infected with no disease signs (18). ASFV can spread between wild pigs and soft ticks by feeding and, infrequently, can spread between wild pigs by direct transmission. Once introduced into the domestic pig population, ASFV can be transmitted directly between pigs and leads to 
mortality rates approaching 100\% (42). The typical clinical signs include high fever, haemorrhagic lesions, cyanosis, anorexia, and ataxia (10). Different organs show severe vascular changes in the acute and subacute forms of ASF, such as renal petechiae and diffuse haemorrhage in lymph nodes, pulmonary oedema, disseminate intravascular coagulation, and thrombocytopenia (28). More recent studies found that porcine macrophage and aortic endothelial cells are good natural host cell lines to support a productive ASFV infection in cell culture $(26,53,74)$.

ASFV is an enveloped DNA virus, and its genome ranges in length from about 170 to $193 \mathrm{kbp}(15)$. The encoded genes are closely spaced in the genome; however, the encoded orientation of neighbouring genes is the same in some genomic regions (20). ASFV has similarities with Poxvirus and Iridovirus, because all of them are cytoplasmic DNA viruses (51). The Spanish BA71V isolate was completely sequenced first, which was well adapted to grow in tissue culture cells. So far, 11 complete ASFV genome sequences have been determined and the numbers of open reading frames (ORFs) are different depending on the isolate (75). The ASFV genome encodes 151 to 167 ORFs. Among them, 110 ORFs are highly conserved in 11 isolates (75). ASFV is icosahedrally symmetric and is a virus which replicates in the cytoplasm of infected cells. ASFV particles are 170 to $190 \mathrm{~nm}$ in diameter and are constituted by complex multi-layered structures (66). The encoded structural proteins are involved in genome replication and viral infection (20). Some research results showed that more than 50 proteins are packaged into virions and work in viral infection, such as pp220, pp62, p72, p54, p30, CD2v, p10, p12, p14.5, and p17. pp220 and pp62 are ASFV polyprotein precursors, and the proteins can be proteolytically cleaved into the mature virion proteins. ASFV p54 and p30 are very important antigenic structural proteins. p72 is the major composition of viral icosahedrons, and is very important in forming the viral capsid in the later expression of viral infection. CD2v is a glycoprotein. It may have a role in the pathogenesis of ASFV infection, and a further one in tissue tropism and immune evasion in the host. p10, p12, p14.5, and p17 proteins are involved in ASFV adsorption and virion transfer. Thus these proteins can be exploited to serve as research targets to analyse the infection mechanism of ASFV. In this review, we discuss the encoded structural proteins of ASFV involved in viral infection, and the molecular mechanism of interaction between these proteins and host cells.

\section{pp220 and pp62 proteins}

To date, ASFV has been found to have 110 ORFs highly conserved in its viral genome (75). There are two ORFs encoding the ASFV polyprotein precursors pp220 and pp62 (or pp60). pp220 with a relative molecular weight of $281.5 \mathrm{kDa}$ belongs to the late proteins in viral infection. This protein is encoded by gene $C P 2475 \mathrm{~L}$ and is cleaved to yield the mature virion proteins p150, p37, p14, and p34 by the virus-encoded SUMO-like protease S273R. pp62 with a relative molecular weight of $60.5 \mathrm{kDa}$ is encoded by gene CP530R, and can be proteolytically cleaved into the mature virion proteins $\mathrm{p} 35$ and $\mathrm{p} 15$ by S273R (3). $\mathrm{p} 150, \mathrm{p} 37, \mathrm{p} 14, \mathrm{p} 34, \mathrm{p} 35$, and p15 play a crucial role in the assembly process of the viral capsid. They account for approximately $30 \%$ of the total amount of viral protein mass, forming the major components of the core shell of the virions (3). Pulse chasing analysis showed that the process of the two polyproteins pp220 and pp62 and virus assembly occur simultaneously. Early research suggested that virus particles assemble in discrete cytoplasmic areas close to the nucleus, referred to as viral factories. Electron microscopic researches showed that virions assemble membranous structures present in the viral factories (4). Further research suggested that processing of polyproteins pp220 and pp62 requires the expression of the major capsid protein $\mathrm{p} 72$, and the expression of pp220 lays the foundation for pp62 processing. Proper processing of pp220 and pp62 is an important sign of mature virions (73). Virus particles without a core or lacking infectiveness can appear if the processing of pp220 and pp62 is prevented (4). Gallardo et al. (29) analysed the antigenicity of pp62, p32, and p54 expressed in insect cells, and these recombinant proteins were used as antigens in ELISA and an immunoblot (IB) test for ASF serological diagnosis. The results showed that the reaction specificity in the IB test is higher than in ELISA, and the specificities of pp62 and p32 are higher than that of $\mathrm{p} 54$.

p37 is one of the major core shell proteins and is cleaved from pp220 by the viral protease S273R that shares sequence similarity with proteases of the SUMO-1 family. p37 is localised to the viral core shell domain and also is the first nucleo-cytoplasmic shuttling protein encoded by ASFV (22). Some research demonstrated that the nuclear export of p37 protein is mediated by both the chromosome region maintenance 1 (CRM1)-dependent and CRM1independent nuclear export pathways (21). In research on detection of the localisation of p37 protein in ASFV-infected cells it was shown that at early stages of infection, p37 localises in distinct nuclear regions, and at later stages, the protein localises exclusively in the cytoplasm (23). All these results reinforce the importance to the ASFV replication cycle of $\mathrm{p} 37$ protein nuclear transport. p34 protein, like p37 protein, is one of the major structural proteins. It was only detected in the membrane fraction, and was only protected from trypsin. Incorrectly processed forms of p34 can be recovered from both the cytosol and membrane fractions $(3,4)$. A sucrose density centrifugation experiment showed that membraneassociated forms of p34 and p150 are assembled into 
large structures suggestive of a viral matrix. The majority of the improperly processed forms of p150 can be recovered from the cytosol; however, the correct product of p150 is selectively recruited to membranes (38). p35 and p15 are the mature products of polyprotein pp62, and the relative molecular weights of the two proteins are $35 \mathrm{kDa}$ and $15 \mathrm{kDa}$ respectively. Densitometric analysis of one- and two-dimensional gels demonstrated that the proteins and the pp220derived products are present in equimolecular amounts in the virus particle. Immunoelectron microscopy showed that the pp62-derived products reside in the core shell which is a matrix-like domain placed between the DNA-containing nucleoid and the inner envelope (72). In summary, pp220, pp62, and their mature proteins have important functions in the assembly of virions and viral infection.

\section{p54 and p30 proteins}

p54 and p30 proteins are the structural proteins involved in viral entry, but while the proteins have similar roles during viral infection, their roles are also materially different. p54 encoded by the gene E183L is a very important ASFV antigenic structural protein with a relative molecular weight of $25 \mathrm{kDa}$. The protein contains a transmembrane domain and a Gly-Gly-X motif, as well as a recognition sequence for processing several ASFV structural proteins. Analysis of the supernatant and precipitation of viral particles containing p54 showed that the protein is located in the lipid outer membrane of virions. p54 is also located by immunoelectron microscopy in the replication factories of infected cells (61). In order to track the behaviour of ASFV in the infected cells in real time, researchers produced an infectious recombinant ASFV to determine the trajectory and speed of intracellular virus movement and thereby visualise the ASFV factory formation dynamics (40). During the process of adaptation to tissue culture, the apparent molecular mass of p54 protein changes. p54 interacts with the microtubular motor complex via direct binding to the light chain 8 (LC8) of the dynein through a motif close to the $\mathrm{C}$-terminus of the protein. The two proteins colocate at the microtubular organising centre during viral infection (3). The direct interaction of DYNLL1, the smallest dynein light chain, with the postsynaptic scaffolding protein gephyrin and the structural protein p54 has been shown by nuclear magnetic resonance (NMR) spectroscopy methods. The results showed that p54 and gephyrin are two targets of DYNLL1, and the sequences of these proteins contain GIQVD and KXTQT motifs with a glutamine which is important for binding $(31,32)$. p5 54 is essential for the recruitment of envelope precursors to assembly sites (62) and plays an important role in virus growth and inducing specific antibodies after inoculation of pigs with attenuated virus strains (61). Therefore, p54 expressed in a baculovirus and $E$. coli system has been exploited in serological diagnosis $(29,31)$. Antibodies to p54 protein inhibited the first step of the viral infection cycle related to viral attachment. Transient expression experiments of p54 in Vero cells demonstrated that p54 can activate the apoptosis of caspase- 3 during the early phase of ASFV infection, and this was the first time an ASFV protein was reported to induce apoptosis $(35,39)$.

Like p54, p30 is one of the early viral proteins. The protein is encoded by the CP204L gene, has a relative molecular weight of $30 \mathrm{kDa}$, and is one of the most antigenic structural proteins involved in ASFV entry (67). Expression of the protein is generally observed from about 2 to $4 \mathrm{~h}$ post-infection, and then continues throughout the infection cycle. Therefore, expression of $\mathrm{p} 30$ indicates that the virus has entered and uncoated, and early virus gene expression has started (47). The yeast two-hybrid system was used to screen a porcine macrophage cDNA library for cellular proteins that may interact with $\mathrm{p} 30$, and heterogeneous nuclear ribonucleoprotein K (hnRNP-K) was identified as the first cellular ligand of p30 (41). p54 and p30 are the antigenic proteins. Researchers demonstrated that a chimeric protein $\mathrm{p} 54 / 30$ retains antigenic determinants and the protein was expressed by a recombinant baculovirus in insect cells and Trichoplusiani larvae (8). The chimeric protein is strongly reactive with sera of pigs with unapparent ASFV infection (8). Oviedo et al. (58) found that recombinant $\mathrm{p} 30$ is more efficient than p54 for antibody detection by ELISA. Thus p 30 should be used as the ELISA antigen, and p54 should be regarded as the appointed antigen for ASFV antibody detection by Western blot. Nevertheless, the combined use of p54 and p30 proteins for serological diagnosis of ASFV could improve the sensitivity of the method. Cubillos et al. (19) evaluated the reactivity of recombinant $\mathrm{p} 30$, p54, and p72 proteins simultaneously in a single reaction. The results showed that p30 is the best diagnostic antigen. Subsequently, Giménez et al. (33) developed a dual matrix indirect ELISA with recombinant $\mathrm{p} 30$ to flexibly detect ASFV antibodies in serum and oral fluid specimens. Antibody-mediated immune mechanisms have an important function in immunity to ASF. DNA vaccines encoding p54 and p30 fused together, namely plasmid DNA encoding two ASFV genes in a frame (pCMV-PQ), induced good antibody responses in mice (6). However, the neutralising antibody response to p54 and p30 is not sufficient for antibody-mediated protection in pigs (8, 54). Argilaguet et al. (7) found that DNA immunisation in pigs could be exponentially improved by adding the extracellular domain of the ASFV haemagglutinin (sHA) to p54 and p30, and pCMV-sHAPQ can induce strong humoral and cellular responses. p54 and p30 proteins serve as the important antigenic structural proteins in viral infection. 


\section{p72 protein}

p72 protein with a relative molecular weight of $73.2 \mathrm{kDa}$ is the major structural protein of ASFV, and it is the crucial antigenic protein encoded by the gene B646L (VP72). p72 with its highly antigenic and immunogenic character serves as the major component of viral icosahedrons. It is very important in forming the viral capsid in late stage expression of virus infection (54). Newly synthesised p72 is distributed evenly between a soluble cytoplasmic pool and a membrane-associated pool bound to the endoplasmic reticulum (ER), and assembles on the ER membrane to form the large capsid or matrix precursor (17). p72 protein was specifically immunoprecipitated by monoclonal antibody (mAb) 135D4 in vitro (11). The results showed that amino acid residues 400 and 404 are necessary for $\mathrm{mAb} 135 \mathrm{D} 4$ reactivity, and these suggested the conformational dependence of the epitope p72 in ASFV entry, and that its expression is an indicator of viral replication (47). A recombinant vaccine based on $\mathrm{p} 72$ and other viral proteins expressed in a baculovirus system was applied to immune pigs (54). p72 antibodies can prevent ASFV binding to macrophages, but the antibodies cannot play a decisive role in antibody-mediated immune protection (54). Chen et al. (16) constructed a recombinant Newcastle disease virus rNDV/p72 expressing ASFV p72 by reverse genetics, and they evaluated its humoral and cellular immunogenicity in a mouse model. The results showed that mice developed a high level of p72specific IgG antibody. Sequence analysis of p72-coding genes from two ASFV strains from Uganda and the Dominican Republic (the latter strain Dominican Republic-2) demonstrated that p72 is highly conserved in strains isolated from different parts of the world. These proved that the antigenicity of p 72 is stable and established a useful molecular basis for ASFV serological tests. Correspondingly, the VP72 gene of ASFV has been successfully expressed in E.coli using a T7 RNA polymerase system. The recombinant protein was purified by size-exclusion highperformance liquid chromatography and was used in serological tests. Sastre et al. (70) developed a duplex pen-side test for simultaneous detection and differentiation of antibodies specific to classical swine fever virus (CSFV) and to ASFV, and these tests were based on the major capsid protein p72 of ASFV and the structural protein E2 of CSFV. Some researchers used small interfering RNA (siRNA) targeting the VP72 and $A 151 R$ genes to control ASFV replication in vitro (44). The results showed that siRNA targeting the genes can reduce both viral replication and the levels of messenger RNA transcripts.

Discernible ASFV serotypes are lacking. Thus, the field strains are grouped genetically by sequencing the C-terminus of the p72 protein, and it provides additional valuable tools for future epidemiological assessment and elucidation of intra-genotypic relationships among the ASFV genotypes (9, 12, 48). Muangkram et al. (52) established a novel phylogenetic analysis and epidemiological comparison based on VP72 gene sequences. They found that 516 sequences of ASFV compiled from GenBank belonged to 44 different genotypes, and ASFV populations of the African continent could be divided into four clades by the analysis of spatial genetic variation. The immunodominant protein $\mathrm{p} 72$ revealed that 13 discrete genotypes were present in Eastern Africa (48). In order to target the single nucleotide polymorphisms (SNPs) in the C-terminal end of the VP72 gene region of the genome, a suspension microarray for the genotyping of ASFV has been developed (45), Gallardo et al. (31) confirmed the usefulness of a combined p72-p54$p B 602 L$ (CVR) gene characterisation approach for investigating the relatedness of ASF epizootics. The first isolate of ASFV from West Africa was successfully identified through PCR amplification and sequencing on the basis of a $280 \mathrm{bp}$ fragment of the VP72 gene, in the course of which changes were found which had resulted in the loss of two out of the seven potential N-glycosylation sites which were conserved among all other isolates in this gene (57). To date, many assay methods have been developed based on the VP72 gene to detect ASFV, such as the linear after the exponential PCR (LATE-PCR), PCR, and real-time PCR (q-PCR) $(37,49,64)$.

\section{CD2v protein}

$\mathrm{CD} 2 \mathrm{v}$ protein, also named PEP402R, resembles the T-lymphocyte surface adhesion receptor CD2 and has a relative molecular weight of $105 \mathrm{kDa}$. It is a glycoprotein which is assembled from a signal peptide (SP), trans-membrane region (TM), and two immunoglobulin-like domains (IG). The cytosolic C-terminal domain of $\mathrm{CD} 2 \mathrm{v}(\mathrm{CD} 2 \mathrm{v}-\mathrm{Ct})$ shares no obvious identity of amino acid sequence with that of the cellular CD2 cytoplasmic domain $(25,63)$. CD2v protein is expressed on $\mathrm{T}$ and NK cells. Moreover, confocal microscopy results suggested that the majority of the expressed CD2v protein is located within cells rather than on the cell surface. $\mathrm{CD} 2 \mathrm{v}$ is located around viral factories during ASFV infection, and the regulatory trans-Golgi network (TGN) protein complex AP-1 is its target (34). The majority of CD2v appears to be located in perinuclear membrane compartments in the absence of an extracellular ligand (43), the protein is expressed late in infection, and the haemadsorption phenomenon is necessary for $\mathrm{CD} 2 \mathrm{v}$ expression in ASFV-infected cells (63). CD2v can be cleaved into $\mathrm{N}$-terminal glycosylated and C-terminal nonglycosylated forms, and this cleaving occurs in the endoplasmic reticulum or Golgi compartments; however, both of the forms coexist in the infected cell with the full length protein (34). CD2v protein is involved in cell-cell adhesion, virulence enhancement, 
and immune response modulation. Its possible role in the pathogenesis of ASFV infection, further role in tissue tropism, immune evasion, and enhancing virus replication in the host was demonstrated (65). CD2v protein can damage the function of lymphocytes, and the expression of this protein has some connection with ASFV spreading in domestic swine. The yeast twohybrid system demonstrated the cytoplasmic tail of $\mathrm{CD} 2 \mathrm{v}$ can interact with the cytoplasmic adaptor protein $\mathrm{SH} 3 \mathrm{P} 7$, and protein $\mathrm{SH} 3 \mathrm{P} 7$ is involved in diverse cellular functions such as vesicle transport and signal transduction (43). The cytoplasmic region of $\mathrm{CD} 2 \mathrm{v}$ protein was proposed as a new genetic marker (69). This character could be used to analyse ASFV strains from different locations and track the virus spread. Serogroup classification of worldwide strains based on the extracellular portion of the protein can be established (13). The genetic locus encoding CD2v protein and $\mathrm{C}$-type lectin proteins mediates $\mathrm{HAI}$ serological specificity, and ASFV CD2v and C type lectin signature sequencing provides a simple method to group ASFV by serotype. Thus it is readily exploitable for the study of ASFV strain diversity in nature and lays a good foundation for eventual vaccine design $(50,69)$.

$\mathrm{CD} 2 \mathrm{v}$ protein is encoded by the EP402R gene. Researchers found that deletion of the EP402R gene from the BA71V virus did not affect viral growth in Vero cell cultures. Frączyk et al. (24) first reported the genetic variability within the gene related to evasion of the host immune system, and they found minor but remarkable genetic diversity in the EP402R gene and demonstrated the slow molecular evolution of circulating ASFV isolates. Comparison of the EP402R gene of ASFV strains collected from 1978 to 2014 showed that Sardinian viruses can be divided into two subgroups. One group includes the historical isolates from 1978 to 1990 , and the second group contains the viruses recovered from 1990 to 2014 (69). It was found that the EP402R and EP153R genes are disrupted in the genome of a natural non-haemadsorbing (non-HAD) isolate with low virulence, the isolate ASFV/NH/P68 (46). However, two recombinant HAD viruses replicated to titre approximately 1,000-fold higher than the non-HAD isolate when the intact EP153R gene was restored. Although the restoration did not increase virus virulence, the symptom of viraemia was observed in a number of pigs, and these results demonstrated a novel role of $\mathrm{CD} 2 \mathrm{v}$ protein in virus replication in ticks (65).

\section{Other structural proteins}

pp220, pp62, p54, p30, p72, and CD2v proteins have been identified as important structural proteins in viral attachment, entry, immune response modulation in the host, and as major components of virions. Besides these, some other structural proteins, such as p10, p12, p14.5, and p17, are encoded by the ASFV genome. They also have important roles in viral infection. p10 protein, with a relative molecular weight of $8.4 \mathrm{kDa}$, is encoded by the $K 78 R$ gene. The protein is an extremely hydrophilic polypeptide with a relatively high content of basic residues $(23 \%)$ and is accumulated in the cell nucleus during viral infection (55). p10 is involved in ASFV adsorption and has DNA binding capacity, either single- or double-stranded (55). The nuclear import ability of p10 was assessed by yeast-based nuclear import assay and the subcellular localisation of p10 in mammalian cells was examined by fluorescence microscopy. The results showed that the protein is actively imported into the nucleus, and 71 to 73 amino acids of p10 are important for the nuclear import (60). p12 protein with a cysteine-rich domain in the $\mathrm{C}$-terminal region is encoded by the $O 61 R$ gene, and is synthesised in the late phase of viral infection (27). Its location in the layer of virions was demonstrated by immunoelectron microscopy. p12 is involved in virus attachment to the host cells, and the membrane proteins on the surface of permissive cells act as receptors for ASFV (14).

p14.5 protein, also called pE120R, is encoded by the $E 120 R$ gene. It is a DNA binding protein with a relative molecular weight of $13.6 \mathrm{kDa}$. p14.5 is synthesised during the late phase of viral infection, and is the necessary protein involved in transferring virions from viral factories to the plasma membrane (5). The posttranslational modifications of $\mathrm{pE} 120 \mathrm{R}$ have been described using two-dimensional gel electrophoresis (2DE) and mass spectrometry (MS), and it was found that the protein was acetylated at the $\mathrm{N}$-terminal alanine (Ala) residue during viral infection (2). p17 is a major structural protein of ASFV and is a trans-membrane protein localised at the viral internal envelope. The protein is essential for the progression of viral membrane precursors toward icosahedral intermediates and virus viability (72).

\section{Conclusions}

There are many proteins encoded by the ASFV genome. These proteins have roles in various stages of the viral infection cycle (Table 1). More than 50 proteins are packaged into virus particles and are the major constituent of virus particles playing a role in the early stages of virus infection. pp220 and pp62 proteins form the major components of the core shell in virions. pp220 and pp62 can be cleaved to yield the mature virion proteins $\mathrm{p} 150, \mathrm{p} 37, \mathrm{p} 14, \mathrm{p} 34, \mathrm{p} 35$, and $\mathrm{p} 15$ by the virus-encoded SUMO-like protease S273R. These proteins have an important role in the assembly process of the viral capsid. p54 locates on the lipid outer membrane of viral particles, and is involved in ASFV entry and serves as the trans-membrane structural protein. p54 is critical for the recruitment and transformation of the ER membranes into the 
Table 1. The structural proteins involved in ASFV infection

\begin{tabular}{|c|c|c|c|}
\hline Protein's name & Gene name & Predicted protein size $(\mathrm{kDa})$ & Protein's function \\
\hline p11.5 & A137R & 21.1 & Involved in virus attachment \\
\hline p10 & A78R & 8.4 & Involved in virus attachment \\
\hline $\mathrm{p} 72$ & B646L & 73.2 & Major capsid protein, involved in virus entry \\
\hline pp220 & $\mathrm{CP} 2475 \mathrm{~L}$ & 281.5 & $\begin{array}{l}\text { Polyprotein precursor of p150, p37, p14, and p34; required for packaging } \\
\text { of nucleoprotein core }\end{array}$ \\
\hline p32 (p30) & CP204L & 23.6 & Phosphorylated and antigenic protein, involved in virus entry \\
\hline pp62 (p60) & CP530R & 60.5 & Polyprotein precursor of p35 and p15 \\
\hline $\mathrm{p} 12$ & O61R & 6.7 & Attachment protein \\
\hline p17 & D117L & 13.1 & $\begin{array}{l}\text { Required for progression of precursor membranes to icosahedral } \\
\text { intermediates }\end{array}$ \\
\hline p54 (j13L) & E183L & 19.9 & $\begin{array}{l}\text { Binds to LC8 chain of dynein, involved in virus entry; required for } \\
\text { recruitment of envelope precursors to the factory }\end{array}$ \\
\hline p14.5 & E120R & 13.6 & $\begin{array}{l}\text { DNA-binding protein, required for movement of virions to plasma } \\
\text { membrane }\end{array}$ \\
\hline $\begin{array}{l}\text { CD2v } \\
(\text { PEP402R) }\end{array}$ & EP402R & 45.3 & $\begin{array}{l}\text { Similar to host } \mathrm{CD} 2 \text { protein, required for binding red blood cells to } \\
\text { infected cells and extracellular virus particles; glycoprotein inserted into } \\
\text { external virus envelope }\end{array}$ \\
\hline
\end{tabular}

precursors of the viral envelope. This protein, together with p30 and other proteins, is regarded as a viable antigen protein in developing serological diagnosis. p72 with its highly antigenic and immunogenic character serves as the major component of viral icosahedrons. The protein locates on the surface of the viral capsid and is expressed late in viral infection. Gene VP72 is used to type the ASFV gene by the sequence of the C-terminus in the VP72 gene, and it is central to a new method for molecular epidemiological research. $\mathrm{CD} 2 \mathrm{v}$ is a glycoprotein and can cause the adsorption of red blood cells around ASFV infected cells and extracellular viral particles. The molecular mechanisms of the function of $\mathrm{CD} 2 \mathrm{v}$ protein are not clear, but researchers found that the protein locates around viral factories during ASFV infection. Some other structural proteins, such as p10, p12, p14.5, and $\mathrm{p} 17$, are involved in ASFV attachment, entry, and replication.

The major target cells of ASFV are swine monocyte-macrophages, but the virus is found in many other cells in the late phase of viral infection. The viral entry mechanism determines viral tropism and pathogenesis, and the pathway of entry in target cells is a dynamin-dependent and clathrin-mediated macropinocytosis process. Present knowledge attests that some viral proteins are involved in ASFV attachment and entry, but the receptors of these proteins are unclear. The viral core transfers to the perinuclear region following ASFV entry into cells, and it starts the early mRNA transcription and translation using enzymes and cytokines. These enzymes and cytokines are packed into the virion interior to provide DNA polymerase of viral replication. ASFV starts its replication in the cytoplasm $6 \mathrm{~h}$ after viral infection. The structural proteins and the enzymes packed into mature virions are encoded at this stage. Transferring the expression from the early gene to the late one is an indicator of the start of ASFV replication. The subsequent procedures include virion assembly in cytoplasm around the nucleus, and the virus nucleoprotein core is packaged to form viral capsid with icosahedrons by the membrane from the double membrane of ER. The packed ASFV is transferred to the plasma membrane by microtubules, and then viral particles bud through the plasma membrane. At last, mature viral particles exit from the host cells.

Additional experiments are needed to illustrate the molecular mechanism of the structural proteins involved in ASFV infection of target cells, although extensive studies have been carried out. Better understanding of the precise mechanism will facilitate the prevention and control of the spread of ASF in the world.

Conflict of Interests Statement: The authors declare that there is no conflict of interests regarding the publication of this article. 
Financial Disclosure Statement: This work was supported by the Natural Science Foundation of China (31072143), Programme of International Science and Technology Cooperation (2012DFG31890).

Animal Rights Statement: None required.

\section{References}

1. Cisek A.A., Dąbrowska I., Gregorczyk K.P., Wyżewski Z.: African Swine Fever Virus: a new old enemy of Europe. Ann Parasitol 2016, 62, 161-167.

2. Alfonso P., Quetglas J.I., Escribano J.M., Alonso C.: Protein PE120R of African swine fever virus is post-translationally acetylated as revealed by post-source decay MALDI mass spectrometry. Virus Gen 2007, 35, 81-85.

3. Alonso C., Miskin J., Hernáez B., Fernandez-Zapatero P., Soto L., Cantó C., Rodríguez-Crespo I., Dixon L., Escribano J.M.: African swine fever virus protein p54 interacts with the microtubular motor complex through direct binding to lightchain dynein. J Virol 2001, 75, 9819-9827.

4. Andrés G., Alejo A., Salas J., Salas M.L.: African swine fever virus polyproteins pp220 and pp62 assemble into the core shell. J Virol 2002, 76, 12473-12482.

5. Andrés G., García-Escudero R., Viñuela E., Salas M.L., Rodríguez J.M.: African swine fever virus structural protein $\mathrm{pE} 120 \mathrm{R}$ is essential for virus transport from assembly sites to plasma membrane but not for infectivity. J Virol 2001, 75, $6758-6768$.

6. Argilaguet J.M., Pérez-Martín E., Gallardo C., Salguero F.J., Borrego B., Lacasta A., Accensi F., Díaz I., Nofrarías M., Pujols J.: Enhancing DNA immunization by targeting ASFV antigens to SLA-II-bearing cells. Vaccine 2011, 29, 5379-5385.

7. Argilaguet J.M., Pérez-Martín E., Nofrarías M., Gallardo C., Accensi F., Lacasta A., Mora M., Ballester M., Galindocardiel I., López-Soria S.: DNA vaccination partially protects against African swine fever virus lethal challenge in the absence of antibodies. PloS One 2012, 7, e40942.

8. Barderas M.G., Rodríguez F., Gómez-Puertas P., Avilés M., Beitia F., Alonso C., Escribano J.M.: Antigenic and immunogenic properties of a chimera of two immunodominant African swine fever virus proteins. Arch Virol 2001, 146, 1681-1691.

9. Bastos A.D.S., Penrith M.L., Crucière C., Edrich J.L., Hutchings G., Roger F., Couacy-Hymann E., Thomson G.R.: Genotyping field strains of African swine fever virus by partial p72 gene characterisation. Arch Virol 2003, 148, 693-706.

10. Blome S., Gabriel C., Beer M.: Pathogenesis of African swine fever in domestic pigs and European wild boar. Virus Res 2013, $173,122-130$.

11. Borca M.V., Irusta P., Carrillo C., Afonso C.L., Burrage T., Rock D.L.: African swine fever virus structural protein p72 contains a conformational neutralizing epitope. Virology 1994, 201, 413-418.

12. Boshoff C.I., Bastos A.D.S., Gerber L.J., Vosloo W.: Genetic characterisation of African swine fever viruses from outbreaks in southern Africa (1973-1999). Vet Microbiol 2007, 121, 45-55.

13. Burmakina G., Malogolovkin A., Tulman E.R., Zsak L., Delhon G., Diel D.G., Shobogorov N.M., Morgunov Y.P., Morgunov S.Y., Kutish G.F.: African swine fever virus serotypespecific proteins are significant protective antigens for African swine fever. J Gen Virol 2016, 97, 1670-1675.

14. Carrascosa A.L., Sastre I., Viñuela E.: Production and purification of recombinant African swine fever virus attachment protein p12. J Biotechnol 1995, 40, 73-86.

15. Chapman D.a., Darby A.C., Da Silva M., Upton C., Radford A.D., Dixon L.K.: Genomic analysis of highly virulent Georgia 2007/1 isolate of African swine fever virus. Emerg Infect Dis 2011, 17, 599-605.

16. Chen X.: Recombinant new castle disease virus expressing African swine fever virus protein 72 is safe and immunogenic in mice. Virol Sin 2016, 31, 1-10.

17. Cobbold C., Wileman T.: The major structural protein of African swine fever virus, p73, is packaged into large structures, indicative of viral capsid or matrix precursors, on the endoplasmic reticulum. J Virol 1998, 72, 5215-5223.

18. Costard S., Mur L., Lubroth J., Sanchez-Vizcaino J.M., Pfeiffer D.U.: Epidemiology of African swine fever virus. Virus Res 2013, 173, 191-197.

19. Cubillos C., Gómez-Sebastian S., Moreno N., Nuñez M.C., Mulumba-Mfumu L.K., Quembo C.J., Heath L., Etter E.M., Jori F., Escribano J.M.: African swine fever virus serodiagnosis: A general review with a focus on the analyses of African serum samples. Virus Res 2013, 173, 159-167.

20. Dixon L.K., Chapman D.A., Netherton C.L., Upton C.: African swine fever virus replication and genomics. Virus Res 2013, 173, 3-14.

21. Eulálio A., Nunes-Correia I., Carvalho A.L., Faro C., Citovsky V., Salas J., Salas M.L., Simões S., De Lima M.C.P.: Nuclear export of African swine fever virus p37 protein occurs through two distinct pathways and is mediated by three independent signals. J Virol 2006, 80, 1393-1404.

22. Eulálio A., Nunes-Correia I., Carvalho A.L., Faro C., Citovsky V., Simões S., De Lima M.C.P.: Two African swine fever virus proteins derived from a common precursor exhibit different nucleocytoplasmic transport activities. J Virol 2004, 78, 9731-9739.

23. Eulálio A., Nunes-Correia I., Salas J., Salas M.L., Simões S., De Lima M.C.P.: African swine fever virus p37 structural protein is localized in nuclear foci containing the viral DNA at early post-infection times. Virus Res 2007, 130, 18-27.

24. Frączyk M., Woźniakowski G., Kowalczyk A., Bocian Ł., Kozak E., Niemczuk K., Pejsak Z.: Evolution of African swine fever virus genes related to evasion of host immune response. Vet Microbiol 2016, 193, 133-144.

25. Galindo I., Almazán F., Bustos M.J., Viñuela E., Carrascosa A.L.: African swine fever virus EP153R open reading frame encodes a glycoprotein involved in the hemadsorption of infected cells. Virology 2000, 266, 340-351.

26. Galindo I., Cuesta-Geijo M.A., Hlavova K., Muñoz-Moreno R., Barrado-Gil L., Dominguez J., Alonso C.: African swine fever virus infects macrophages, the natural host cells, via clathrin-and cholesterol-dependent endocytosis. Virus Res 2015, 200, 45-55.

27. Galindo I., Viñuela E., Carrascosa A.L.: Protein cell receptors mediate the saturable interaction of African swine fever virus attachment protein p12 with the surface of permissive cells. Virus Res 1997, 49, 193-204.

28. Galindo-Cardiel I., Ballester M., Solanes D., Nofrarías M., López-Soria S., Argilaguet J.M., Lacasta A., Accensi F., Rodríguez F., Segalés J.: Standardization of pathological investigations in the framework of experimental ASFV infections. Virus Res 2013, 173, 180-190.

29. Gallardo C., Blanco E., Rodríguez J.M., Carrascosa A.L., Sanchez-Vizcaino J.M.: Antigenic properties and diagnostic potential of African swine fever virus protein pp62 expressed in insect cells. J Clin Microbiol 2006, 44, 950-956.

30. Gallardo C., Fernández-Pinero J., Pelayo V., Gazaev I., Markowska-Daniel I., Pridotkas G., Nieto R., FernándezPacheco P., Bokhan S., Nevolko O., Drozhzhe Z., Pérez C., Soler A., Kolvasov D., A_rias M.: Genetic variation among African swine fever genotype ii viruses, eastern and central Europe. Emerg Infect Dis 2014, 20, 1544-1547.

31. Gallardo C., Mwaengo D.M., Macharia J.M., Arias M., Taracha E.A., Soler A., Okoth E., Martín E., Kasiti J., Bishop R.P.: Enhanced discrimination of African swine fever virus isolates through nucleotide sequencing of the p54, p72, and pB602L (CVR) genes. Virus Gen 2009, 38, 85-95. 
32. García-Mayoral M.F., Rodríguez-Crespo I., Bruix M.: Structural models of dynll1 with interacting partners: African swine fever virus protein $\mathrm{p} 54$ and postsynaptic scaffolding protein gephyrin. Febs Lett 2011, 585, 53-57.

33. Giménez-Lirola L.G., Lina M., Belen R., Mark M., Sun Y., Sergio L., Christa G., Hank H.D.L., Rowland, R.R.R., Carmina, G.: Detection of African swine fever virus antibodies in serum and oral fluid specimens using a recombinant protein 30 (p30) dual matrix indirect ELISA. Plos One 2016, 11, e0161230.

34. Goatley L.C., Dixon L.K.: Processing and localization of the African swine fever virus $\mathrm{CD} 2 \mathrm{v}$ transmembrane protein. J Virol 2011, 85, 3294-3305.

35. Gómez-Puertas P., Escribano J.M.: Blocking antibodies inhibit complete African swine fever virus neutralization. Virus Res 1997, 49, 115-122.

36. Woźniakowski G., Kozak E., Kowalczyk A., Łyjak M., Pomorska-Mól M., Niemczuk K., Pejsak Z.: Current status of African swine fever virus in a population of wild boar in eastern Poland (2014-2015). Arch Virol 2016, 161, 189-195.

37. Haines F.J., Hofmann M.A., King D.P., Drew T.W., Crooke H.R.: Development and validation of a multiplex, realtime (RT-PCR) assay for the simultaneous detection of classical and African swine fever viruses. Plos One 2013, 8, e71019.

38. Heath C.M., Windsor M., Wileman T.: Membrane association facilitates the correct processing of pp220 during production of the major matrix proteins of African swine fever virus. J Virol 2003, 77, 1682-1690.

39. Hernáez B., Díaz-Gil G., García-Gallo M., Ignacio Q.J., Rodríguez-Crespo I., Dixon L., Escribano J.M., Alonso C.: The African swine fever virus dynein-binding protein p54 induces infected cell apoptosis. Febs Lett 2004, 569, 224-228.

40. Hernaez B., Escribano J.M., Alonso C.: Visualization of the African swine fever virus infection in living cells by incorporation into the virus particle of green fluorescent proteinp54 membrane protein chimera. Virology 2006, 350, 1-14.

41. Hernaez B., Escribano J.M., Alonso C.: African swine fever virus protein $\mathrm{p} 30$ interaction with heterogeneous nuclear ribonucleoprotein $\mathrm{k}$ (hnRNP-K) during infection. Febs Lett 2008, 582, 3275-3280

42. Howey E.B., O’Donnell V., Ferreira H.C.D.C., Borca M.V., Arzt J.: Pathogenesis of highly virulent African swine fever virus in domestic pigs exposed via intraoropharyngeal, intranasopharyngeal, and intramuscular inoculation, and by direct contact with infected pigs. Virus Res 2013, 178, 328-339.

43. Kayjackson P.C., Goatley L.C., Cox L., Miskin J.E., Parkhouse R.M., Wienands J., Dixon L.K.: The CD2v protein of African swine fever virus interacts with the actin-binding adaptor protein SH3P7. J Gen Virol 2004, 85, 119-130.

44. Keita D., Heath L.E.: Control of African swine fever virus replication by small interfering RNA targeting the A151R and VP72 genes. Antivir Ther 2010, 15, 727-736.

45. Leblanc N., Cortey M., Pinero J.F., Gallardo C., Masembe C., Okurut A.R., Heath L., Heerden J.V., Sánchez-Vizcaino J.M., Ståhl K.: Development of a suspension microarray for the genotyping of African swine fever virus targeting the SNPs in the c-terminal end of the p72 gene region of the genome. Transbound Emerg Dis 2013, 60, 378-383.

46. Leitão A., Cartaxeiro C., Coelho R., Cruz B., Parkhouse R.M., Portugal F., Vigário J.D., Martins C.L.: The non-haemadsorbing African swine fever virus isolate $\mathrm{ASFV} / \mathrm{NH} / \mathrm{P} 68$ provides a model for defining the protective anti-virus immune response. J Gen Virol 2001, 82, 513-523.

47. Lithgow P., Takamatsu H., Werling D., Dixon L., Chapman D. Correlation of cell surface marker expression with African swine fever virus infection. Vet Microbiol 2014, 168, 413-419.

48. Lubisi B.A., Bastos A.D.S., Dwarka R.M., Vosloo W. Molecular epidemiology of African swine fever in east Africa. Arch Virol 2005, 150, 2439-2452.

49. Luo Y., Atim S.A., Shao L., Ayebazibwe C., Yuan S., Yan L., Ji S., Meng X.Y., Su L., Li Y.: Development of an updated PCR assay for detection of African swine fever virus. Arch Virol 2016, 162, 191-199.

50. Malogolovkin A., Burmakina G., Tulman E.R., Delhon G., Diel D.G., Salnikov N., Kutish G.F., Kolbasov D., Rock D.L.: African swine fever virus $\mathrm{CD} 2 \mathrm{v}$ and c-type lectin gene loci mediate serological specificity. J Gen Virol 2015, 96, 866-873.

51. Misinzo G., Kwavi D.E., Sikombe C.D., Makange M., Peter E., Muhairwa A.P., Madege M.J.: Molecular characterization of African swine fever virus from domestic pigs in northern Tanzania during an outbreak in 2013. Trop Anim Health Pro 2014, 46, 1199-1207.

52. Muangkram Y., Sukmak M., Wajjwalku W.: Phylogeographic analysis of African swine fever virus based on the p72 gene sequence. Genet Mol Res 2015, 14, 4566-4574.

53. Muñoz-Moreno R., Galindo I., Cuesta-Geijo M., Barrado-Gil L., Alonso C.: Host cell targets for African swine fever virus. Virus Res 2015, 209, 118-127.

54. Neilan J.G., Zsak L., Lu Z., Burrage T.G., Kutish G.F., Rock D.L.: Neutralizing antibodies to African swine fever virus proteins p30, p54, and p72 are not sufficient for antibodymediated protection. Virology 2004, 319, 337-342.

55. Nunes-Correia I., Rodríguez J.M., Eulálio A., Carvalho A.L., Citovsky V., Simões S., Faro C., Salas M.L., De Lima, M.C.P.: African swine fever virus p10 protein exhibits nuclear import capacity and accumulates in the nucleus during viral infection. Vet Microbiol 2008, 130, 47-59.

56. Nurmoja I., Petrov A., Breidenstein C., Zani L., Forth J.H., Beer M., Kristian M., Viltrop A., Blome S.: Biological characterization of African swine fever virus genotype ii strains from north-eastern Estonia in european wild boar. Transbound Emerg Dis 2017. Doi: 10.1111/tbed.12614.

57. Odemuyiwa S.O., Adebayo I.A., Ammerlaan W., Ajuwape A.T.P., Alaka O.O., Oyedele O.I., Soyelu K.O., Olaleye D.O., Otesile E.B., Muller C.P.: An outbreak of African swine fever in Nigeria: virus isolation and molecular characterization of the $v p 72$ gene of a first isolate from west Africa. Virus Gen 2000, 20, 139-142.

58. Oviedo J.M., Rodríguez F., Gómez-Puertas P., Brun A., Gómez N., Alonso C., Escribano J.M.: High level expression of the major antigenic African swine fever virus proteins p54 and p30 in baculovirus and their potential use as diagnostic reagents. J Virol Methods 1997, 64, 27-35.

59. Penrith M.L., Vosloo W., Jori F., Bastos A.D.: African swine fever virus eradication in Africa. Virus Res 2013, 173, 228-246.

60. Rhee Y., Gurel F., Gafni Y., Dingwall C., Citovsky V.: A genetic system for detection of protein nuclear import and export. Nat Biotechnol 2000, 18, 433-437.

61. Rodriguez F., Ley V., Gómez-Puertas P., García R., Rodriguez J., Escribano J.: The structural protein p54 is essential for African swine fever virus viability. Virus Res 1996, 40, 161-167.

62. Rodríguez J.M., García-Escudero R., Salas M.L., Andrés G.: African swine fever virus structural protein p54 is essential for the recruitment of envelope precursors to assembly sites. J Virol 2004, 78, 4299-4313.

63. Rodríguez J.M., Yáñez R.J., Almazán F., Viñuela E., Rodriguez J.F.: African swine fever virus encodes a CD2 homolog responsible for the adhesion of erythrocytes to infected cells. J Virol 1993, 67, 5312-5320.

64. Ronish B., Hakhverdyan M., Ståhl K., Belák S., Leblanc N., Wangh L.: Design and verification of a highly reliable linearafter-the-exponential PCR (LATE-PCR) assay for the detection of African swine fever virus. J Virol Methods 2011, 172, 8-15.

65. Rowlands R.J., Duarte M.M., Boinas F., Hutchings G., Dixon L.K.: The CD2v protein enhances african swine fever virus replication in the tick vector, Ornithodoros erraticus. Virology 2009, 393, 319-328.

66. Salas M.L., Andrés G.: African swine fever virus morphogenesis. Virus Res 2013, 173, 29-41.

67. Sánchez E.G., Quintas A., Nogal M., Castelló A., Revilla Y.: African swine fever virus controls the host transcription and 
cellular machinery of protein synthesis. Virus Res 2013, 173, 58-75.

68. Sánchez-Vizcaíno J.M., Mur L.: African swine fever (ASF): Five years around Europe. Vet Microbiol 2013, 165, 45-50.

69. Sanna G., Dei G.S., Bacciu D., Angioi P.P., Giammarioli M., De Mia G.M., Oggiano A.: Improved strategy for molecular characterization of African swine fever viruses from Sardinia, based on analysis of $\mathrm{p} 30, \mathrm{CD} 2 \mathrm{v}$ and $\mathrm{I73R} / \mathrm{I} 329 \mathrm{~L}$ variable regions. Transbound Emerg Dis 2016. Doi: 10.1111/tbed.12504.

70. Sastre P., Pérez T., Costa S., Yang X., Räber A., Blome S., Goller K.V., Gallardo C., Tapia I., García J.: Development of a duplex lateral flow assay for simultaneous detection of antibodies against African and classical swine fever viruses. J Vet Diagn Invest 2016, 28, 543-549.

71. Śmietanka K., Woźniakowski G., Kozak E., Niemczuk K., Frączyk M., Bocian Ł., Kowalczyk A., Pejsak Z.: African swine fever epidemic, Poland, 2014-2015. Emerg Infect Dis 2016, 22, 1201-1207.

72. Suárez C., Gutiérrez-Berzal J., Andrés G., Salas M.L., Rodríguez J.M.: African swine fever virus protein p17 is essential for the progression of viral membrane precursors toward icosahedral intermediates. J Virol 2010, 84, 7484-7499.

73. Suárez C., Salas M.L., Rodríguez J.M.: African swine fever virus polyprotein pp62 is essential for viral core development. J Virol 2010, 84, 176-187.

74. Vallée I., Tait S.W., Powell P.P.: African swine fever virus infection of porcine aortic endothelial cells leads to inhibition of inflammatory responses, activation of the thrombotic state, and apoptosis. J Virol 2001, 75, 10372-10382.

75. Villiers E.P.D.: Phylogenomic analysis of 11 complete African swine fever virus genome sequences. Virology 2010, 400, $128-136$. 